\title{
SCHEPPING EN EVOLUTIE*
}

\section{Inleiding}

De heide woorden die in de titel van deze voordracht naast elkander staan helben voor de Christen relaties tot twee verschillende sferen van het mens-zijn. Het woord "schepping" behoort tot de sfeer van het religieuze geloven, daar het ons in beslag neemt vanuit de Goddelijke openbaring in de Bijbel. Het woord "evolutie" daarentegen, komt uit de sfeer van de menselijke ervaring via het wetenschappelijk onderzoek, dat het worden van de wereld waarvan wij deel uitmaken zo veel mogelijk tracht te kennen en te hegrijpen. Het bijeenvoegen van deze twee woorden in de titcl wijst er dus reeds op dat, hoewel in deze voordracht een meer toegespitst vraagstuk behandeld wordt, dit slechts kan geschieden tegen de achtergrond van de algemene vraagstukken van „Bijbel en wetenschap", en "geloof en wetenschap". Wij zullen in het navolgende geleidelijk deze problematiek benaderen.

\section{De wetenschappelijke gegevens}

Daartoe beginnen wij met heknopt na te gaan over welke constateringen betreffende het oudste verleden van deze aarde en haar bewoners wij momenteel beschikken.

De ouderdom van de aarde is in de orde van $3-5$ milliard jaren. Er zijn geen aanduidingen dat van het allereerste begin af levende organismen op onze planeet aanwezig zijn geweest. De oudste resten van organismen, daterend van $\mathrm{l}-2$ milliard jaren geleden betreffen lagere planten, bacteriën en algen. Omstreeks de begin-tijd van de periode van het zogenaande Cambrium, zo ongeveer 600 millioen jaren geleden kwamen er reeds dieren op aarde voor, behorende tot vrijwel alle groepen van ongewervelde dieren, zoals één-celligen, sponsen, holtedieren, gelede wormen, geleedpotige dieren, weekdieren, en armpotigen. De groep der gewervelde dieren is eerst later ontstaan, nl. in het Ordovicium, ongeveer 400 millioen jaren geleden. De eerste vertegenwoordigers van deze diergroep) waren de zo. kaaklozen ( $\Lambda$ gnatha), die in een grote veclvormigheid voorkwamen, maar naderhand grotendeels zijn uitgestor. ven, zodat er momenteel nog slechts enkele soorten van leven, de zg. prikken en slijmalen (Cyclostomata).

Wanneer wij de geschiedenis van de gewervelde dieren verder vervolgen, zien wij dat in de latere honderden millioenen jaren successie-

- Openbare voordrag aan die Polchefstroomse Universiteit vir C.H.O. op 17 Augustus 1961, tydens die skrywer se verbly as gas-professor an die P.U. vir C.H.O. 
velijk zijn opgetreden de vissen, de amphibieën (salamanders, padden, e.d.), de reptielen (hagedissen, slangen, schildpadden, krokodillen, e.d.), de vogels en de zoogdieren. leder dezer groepen vertonde reeds vrijwel meteen een grote veelvormigheid. Dit geldt wel in het bijzonder de groep der zoogdieren. Onder hen is de orde der Primates, wartoe wij zelf zoologisch bezien behoren, voor ons wel het meest interessant. Ongeveer 60 millioen jaren geleden kwamen de eerste vertegenwoordigers hiervan voor, behorende tot de halfapen, terwijl ongeveer 35 millioen jaren geleden de eerste apen en mensapen voorkwamen.

De geschiedenis van de mens begint met het Pleistoceen, de periode van de vier grote ijstijden op het $\mathrm{N}$.-halfrond, ongeveer $1-2$ millioen jaren geleden. De oudste organismen waarbij de vraag opgeworpen kan worden of het mensen waren, zijn de zg. Australopithecinae, waarvan sinds 1924 vnl. in Zuid-Afrika (Taungs, Sterkfontein, Makapansgat, enz.) fossiele resten zijn gevonden. Hoewel zij enerzijds door verschillende kenmerken, zoals geringe schedelinhoud $1450-800 \mathrm{ml}$., mensapen tot $685 \mathrm{ml}$.), sterke kaken, en het soms voorkomen van heenkammen op de schedel, sterk op mensapen gelijken, vertonen zij anderzijds zoer veel menselijke trekken, zoals in de bouw van het gebit, terwyl vooral de ligging van het achterhoofdsgat en de bouw van het heupheen er op wijzen dat deze wezens zich rechtopgaand (alleen op de achterextremiteiten, bipedie' voortbewogen.

Op deze Australopithecinae volgen dan de Pithecanthropus-vormen, die vnl. op Java, in China (Sinanthropus), maar ook op enkele plaatsen in Afrika zijn gevonden. Deze organismen leeflen ongeveer een half millioen jaren geleden. Hun schedelinhoud variëerde van $775-1225$ $\mathrm{ml}$, en was dus aanmerkelijk hoger dan die van de vorige groep. Nog grotere schedels hadden de Neanderthalers, warvan fossielen op vele plaatsen in de Oude Wereld zijn aangetroffen. Hun schedelinhoud bedroeg nl. $1200-1600 \mathrm{ml}$. $\mathrm{Zij}$ leefden van ongeveer 150.000 tot 60 , a 70.000 jaren geleden. Deze groep werd op aarde vervangen door do huidige mens, Homo sapiens, die in zijn duidelijke vorm ongeveer 60) a 100,000 jaren oud is en vall alle voorgaande vormen anatomiscl verschilt o.d. door het hezit van cen hoog voorhoofd, een afgerond achterhoofd, en een duidelijke kin. Zijn herseninhoud ledraagt gemiddeld ongeveer $1350 \mathrm{ml}$.

In verband met het vraagstuk naar het ontstaan van de mens is het belangrijk ook kort enkele gegevens van geheel andere aard te vermelden. Deze betreffen nl. de culturele voorthrengselen, waardoor de mens zich onderscheidt van de dieren. Van de fossicle Homo sapiens kent men zeer veel cultuurproducten. Allereerst heeft men vele gebruiksvoorwerpen gevonden zoals stenen en henen werktuigen, maar verder ook 
olielampen, naakden, ringen en armbanden, fluiten, heeldjes en de bekende, dikwijls polychrome, grottenafbeeldingen, die in grote aantallen, met name in Frankrijk, zijn aangetroffen. Zij begroeven verder veelal hun doden op cen bepaalde wijze. Kortom zij vertonen een samengestelde cultuur en kunnen niet anders dan als mensen beschouwd worden. Voor de Neanderthalers geldt, hoewel de culturele resten die van hen bekend zijn minder gevariëerd zijn, hetzelfide. Wanneer wij nog verder terug. gaan in het Pleistoceen worden de gegevens schaarser, en krijgen wij vormen waarbij over de vraag of het dieren of mensen waren getwist kan worden. Jit geldt vooral voor de reeds genoemde Australopithecinae. De gedachte van Dart, uit Johanneshurg, dat deze wezens gebruik maakten van zeer weinigbewerkte voorwerpen vervaardigd van beenderen, gebitten en horens (,osteodontokeratic culture"), wordt lang niet algemeen aanvaard, hoewel enkele van zijn voorbeelden een overtuigende indruk maken. Het feit dat men bij de oudste Pleistocene mensachtige vormen niet met absolute zekerheid bijhehorende culturele voortbrengselen heeft gevonden, neemt echter niet weg dat men algemeen meent dat gedurende het gehele Pleistoceen menselijke activiteiten waarneembaar zijn. Men kent nl. van dit gehele tijdperk culturen van stenen werktuigen, vrijwel over de gehele Oude Wereld heen. Dat wil dus zeggen dat men van zeer veel gebieden gebruiksvoorwerpen kent, maar slechts op enkele plaatsen fossicle resten heeft aangetroffen.

\section{Ilet evolutie-vraagstuk}

Het in de vorige paragraal beknopt geschetste beeld van een geleidelijk met levende organismen gevuld wordende aarde, heeft de moderne biologie tot de opvatting van een genetische samenhang, van een evolutie-verband, tussen deze organismen gevoerd. Naast het algemene argument dat de aarde aanvankelijk onbewoond was, daarna eenvoudige plantaardige organismen en vervolgens dieren voorkwamen, waarna ten slotte als laatste en hoogste reeks in de lange keten der gewervelde dieren de mens optrad, kunnen voor deze gedachte nog vele andere worden aangevoerd.

Zo acht de biologie, nadat dit met name door Darwin reeds een eeuw geleden was gesteld, het als vaststaand aangetoond dat de soorten (species), als gevolg van het optreden van mutaties, in samenwerking met invloeden als selectie en isolatie, kunnen veranderen in die zin dat vanuit bestaande soorten nieuwe soorten kunnen voortkomen. Eveneens pleitend voor de evolutie-gedachte is dat lov. bij de ontstaansgeschiedenis van de verschillende klassen der gewervelde dieren een duidelijke paralleliteit geconstateerd kan worden tussen de historische opeenvolging (kaaklozen, vissen, amplibieën, enz.) en de verschillen in de bouw 
van de orgaanstelsels. Zo wordt de bouw van bv. de hersenen in deze reeks stecds gecompliceerder.

Er zijn echter ook argumenten van geheel andere aard, samenhangend met de fundamentele structuren en functies, die aanleiding tot de evolutiegedachte geven. In de aardse werkelijkheid ervaren wij dingen van verschillend karakter: levenloze dingen (water, gassen, kristallen, stenen, cnz.), planten, dieren, en mensen. In hun duidelijke vorm zijn deze door hepaalde eigenschappen karakteristiek verschillend. Zo onderscheiden de planten zich van de levenloze dingen doordat zij stofwisselingsverschijnselen, groei, reproductie, en bv. een functie-verdeling vertonen. De dieren verschillen van de planten doordat zij een actieve oriëntatie l.o.v. het milieu kunnen hewerkstelligen, doordat zij een prikkelbaarheid hezitten door middel van een systeem van zintuigen, zenuwen, en zogenaamde effectoren als spieren of andere contractiele elementen. Verder vertonen zij typische gedragingen. De mens, ten slotte, verschilt van de dieren onder meer door zijn begripsspraak, zijn mogelijkheid van ethische keuzen, door zijn culturele activiteiten, en zijn geloofsfunctie.

Deze verschillen tussen de dingen ervaart ieder mens. En de bioloog is veelal geneigd deze verschillen als fundamenteel te accepteren, maar hij weet tevens dat de grenzen mogelijk niet zo scherp liggen als men veelal denkt: de virussen die een soort tussenvormen tussen de levenloze dingen en de organismen schijnen te zijn, vele micro-organismen die tussen planten- en dicrenrijk instaan, en de merkwaardige $\Lambda$ ustralopithecinae die, zeker in hun bouw, mengsels van animale en humane eigenschappen vertoonden.

De bioloog is zich echter tevens bewust dat het evolutie-vraagstuk cen dimensie bezit waar de niet-bioloog veelal geen weet van heeft, doordat het hem aan biologische vakkennis ontbreekt. De moderne biologie in al haar geledingen stapelt namelijk dagelijks meer argumenten op voor de gedachte van een zeer hechte samenhang tussen de dingen in deze werkelijkheid. Iets daarvan zij hier vermeld. Tegenover de karakteristieke verschillen die hierboven werden aangeduid, staan nl. vele fundamentele overeenkomsten. Zo zijn de levende organismen opgebouwd uit dezelfde chemische elementen die in de levenloze natuur voorkomen, en wisselen deze ook voortdurend met haar uit. In hen gelden eveneens de wetmatigheden van behoud van materie en energie. Ja, alle fundamentele physische en chemische wetmatigheden behouden in de organismen hun kracht, zodat de in hen verlopende reacties individueel in apparaten in het laboratorium zich kunnen afspelen. Kortom, het kan wel zo gesteld worden dat in de organismen een groot stuk levenloze natuur is opgenomen. Dit wijst op een zeer hecht en onverbrekelijk contact, waarvan door iedere opvatting over het ontstaan der organismen rekenschap 
gegeven moet worden. Iets dergelijks komt naar voren indien wij dieren met planten vergelijken. Er zijn verschillen zoals wij zagen, maar voor een bioloog zijn de overeenkomsten zeker even duidelijk. Men heeft geconstateerd dat de stofwisseling der weefsels in alle organismen in grote trekken volgens dezelfde principes verloopt. Alle organismen (planten en dieren) zijn uit cellen of cellulaire structuren opgebound, die overrenkomstige celkernen on andere specifieke orgaincellen bevalten. Steeds vinden wij de processen der celdelingen, steeds chromosomen, steeds de fundamentele ophouw uit nucleinezuren en protënen. De erfelijkheidsverschijuselen verlopen in planten- en dierenrijk volgens dezelfde principes. Kortom, het is alsof in de dieren een enorm stuk plantaardig leven is opgenomen; of, anders gesteld, naast hun verschillen vertonen planten en dieren enorme fundamentele overeenkomsten. Ook deze vitale gemeenschappelijkheid dient bij de ontstaansvraag ernstig overwogen te worden en pleit met grote klem voor de gedachte van een historische samenhang. Ten slotte geldt hetzelfde indien mens en dier vergeleken worden. Ook de mens vertoont dezelfde stofwisselingsmechanismen als de overige organismen. Ook hij heeft een cellulaire ophouw, ook zijn erfelijkheidsprocessen volgen dezelfde wetmatigheden. Hij hevat dezelfde organen als de zoogdieren: hart, nieren, longen, huid, zenuwen, enz. Zijn ontwikkeling en gezondheid worden eveneens beïnvloed door vitaminen en hormonen. Zijn bloedproteïnen stemmen in loge mate overeen met die van de apen, terwijl bv. zijn bloedgroepen eveneens voorkomen bij de mensapen: gibbon, orang, chimpansee, en gorilla.

Kortom, liet is alsol in de mens een samenhangend stuk dierlijk organisme is opgenomen en hiermee dient ook iedere ernstige opvatting over het ontstaan van de mens rekening te houden.

Het zijn onder meer deze gegevens die de huidige biologie tot evolutie-beschouwingen hebben gevoerd. Om ons eigen standpunt duidelijk te kumnen aangeven dient de nadruk gelegd te worden op het volgende. Allereerst zijn er gevallen bekend waarbij aan een opgetreden evolutieproces redelijkerwijs niet getwijfeld kan worden. Zo wanneer men een grote serie fossielen vindt in mooi aaneengesloten aardlagen en waarbij men een soort zich als op een film in enkele nieuwe soorten ziet splitsen. In dergelijke gevallen kunnen wij de evolutie als een gegeven aanvaarden. Boven de directe gegevens uit gaat een evolutie-theorie. Dit zijn bv. beschouwingen waarbij op grond van argumenten van verschillende, elkander versterkende, aard de mening naar voren wordt gebracht dat de amphibieën uit vissen zijn voortgekomen. Een dergelijke evolutie-theorie heeft een zuiver vakwetenschappelijke betekenis, zoals theorieen in het algemeen tot de onmisbare denkapparatuur van iedere wetenschap behoren.

Geheel anders, en daarmee raken wij de kern van ons vraagstuk, 
is het wanneer van evolutionisme wordt gesproken. Dit woord is van toepassing op die denkwijzen waarbij het biologisch evolutie-begrip gebruikt wordt om een totale en exclusieve verklaring van de ontstaansen wordingswijze van deze gehele werkelijkheid te geven. De betekenis van het evolutionisme gaat dan ook ver over de grenzen van de vak. wetenschap heen, beperkt zich niet eens tot het gehied van de filosofie, maar raakt zelfs de religicuze kern van de mens.

Het toonaangevend evolutionisme, gepropageerd vanuit de hiologie en voortgekomen uit het materialisme van de vorige ceuw, vertoont cen aantal opvallende kenmerken. In de eerste plaats erkent het geen essentiële, geen radicale verschillen tussen levenloze dingen, levende organismen, en mensen, in die zin dat deze door onherleidbare aspecten van elkander te onderscheiden zijn. De natuurwetten zijn, vervolgens, in deze beschouwingen volkomen autonoom, de ontwikkeling ging niet volgens plan, had geen ("vooropgesteld") doel, en miste een buiten zichzelf heenwijzende zin. De kern van deze beschouwingen is dat het geloof dat er een persoonlijk God bestaat, die deze werkelijkheid geschapen heeft en leidt, door de aanhangers hiervan niet aanvaard kan worden. Het is duidelijk dat geen Christen het evolutionisme kan aanvaarden, daar het onverenighaar is met zijn diepste overtuigingen.

De afwijzing van het evolutionisme behoeft echter allerminst impliciet een ontkenning van het bestaan van een evolutie-proces met zich mee te brengen. Het is juist de taak van Christen-onderzoekers en wel in het bijzonder van hen die verbonden zijn aan universiteiten die het praedikaat "Christelijk" voeren, na te gaan wat tegenover dit onzes inziens foutieve evolutionisme gesteld behoort te worden. $O_{p}$ d deze vraag zal in de volgende paragraaf nader worden ingegaan.

\section{Schepping en evolutie}

Hierboven werd reeds gesteld dat het speciale vraagstuk dat in deze voordracht behandeld wordt samenhangt met een ruimere problematiek, nl. die van Bijbel en geloof enerzijds in hun relatie tot de wetenschap, in ons geval de natuurwetenschap, anderzijds. De benadering van dit laatste vraagstuk is in reformatorische kringen in het verleden veelal fragmentarisch geweest, in die zin dat men geneigd was individuele uitspraken of mededelingen in de Bijbel direct toe te passen in de natuurwetenschap. Enkele voorbeelden kunnen dit verduidelijken. $Z_{o}$ voerde de uitdrukking ,zon sta stil" uit Jozua $10: 12$ tot een grond. leggende geocentrische beschouwing in de astronomie, de uitdrukking „, naar hun aard" in Genesis 1 vocrde tot de basale opvatting der soortconstantie in de biologie, uit de geslachtsregisters werd de ouderdom van de aarde berekend, het verhaal van de zondvloed voerde tot algemene 
gcologische theorieën over de wording van de aardkorst en de fossielen, cn het verhaal van de zondeval voerde tot speciale opvattingen in de parasitologie. Deze wijze van benadering van het vraagstuk van Bijlel en Natuurwetenschap sproot voort uit de gedachte, dat het openharingskarakter van de Bijlsel met zich meebracht dat daaraan natuurwetenschappelijke theorieën en zelfs gegevens te ontlenen waren.

Het feit dat alle bovengenoemde voorbeelden, en nog vele andere, in de loop van de laatste eeuwen beslist onjuist zijn gebleken, moet ons tot de vaste overtuiging voeren dat deze methode onjuist is. $\mathrm{Zij}$ is niet alleen onjuist maar ook zeer schadelijk voor de verbreiding van het evangelie. Hoe dikwijls heeft immers het besef van de onjuistheid van een dergelijke gedachte niet tot een verlammende geloofstwijfel gevoerd, en hoe dikwijls zijn juist deze beschouwingen niet een obstakel voor de buitenstaanders geweest?

De geschiedenis heeft ons daarom langzamerhand wel geleerd dat de Bijhel ons beslist geen natuurwetenschappelijke theorieën en gegevens levert. De Bijhel, daarentegen, openbaart ons werkelijkheden die de mens en dus de natuurwetenschap nimmer zelf kan ontdekken. Wij mogen dus nimmer bepaalde teksten naast natuurwetenschappelijke vraagstukken leggen en dan aan de teksten een bindende vakwetenschappelijke uitspraak ontlenen. $W_{i j}$ dienen echter door het lezen van de Bijbel in ons hart doordrongen te worden van Gods openbaring van de meest fundamentele en religieus beslissende werkelijkheden, om deze ook in ons wetenschap. pelijk denken als de meest radicale uitgangspunten mee te nemen. En dat voert ons dan, zoals hierboven geschiedde, bv. tot een afwijzing van het evolutionisme.

$W_{i j}$ zullen nu nagaan welke consequenties deze beschouwing heeft voor het vraagstuk van schepping en evolutie. In Christelijke kringen zijn verschillende opvattingen over dit vraagstuk naar voren gebracht. Wij zullen deze schematisch bezien:

a. De eerste lag geheel in de lijn van de hierboven geschetste benaderingswijze. Zij hield in dat 7000 à 8000 jaren geleden in tijdsdagen van 24, uur door God alle soorten geschapen zijn, zoals wij hen ook tegenwoordig nog kennen. In deze opvatting is voor evolutie geen plaats. b. Toen echter steeds overtuigender bleek dat de aarde millioenen jaren oud was, werd de mening geopperd dat de dagen in Genesis 1 mogelijk perioden van lange duur zijn geweest, of dat tussen de dagen dergelijke perioden aanwezig zijn geweest. Ook deze opvatting staat niet open voor evolutic.

c. Aanhangers van een derde opvatting aanvaardden de hoge ouderdom van de aarde, maar kwamen eveneens onder de indruk van de resultaten van het fossialen-onderzoek en van de biologie betreffende de verander. 
lijkheid der soorten. $\mathrm{Zij}$ accepteerden daarom een zekere mate van evolutie, en meenden de voorgaande opvatting in die zin te moeten wijzigen dat door God successievelijk grondvormen in deze werkelijkheid geschapen zijn, die daarna door een natuurlijk proces van evolutie tot de grote verscheidenheid voerden.

d. Een laatste opvatting, die hier genoemd moet worden, gaat nog verder dan de voorgaande en aanvaardt eigenlijk een generale evolutie van de levenloze materie tot en met de mens, met dien verstande dat door God het leven en de ziel op bepaalde momenten in deze werkelijkheid zijn ingeschapen.

Wat al deze beschouwingen gemeenschappelijk hebben is dat God in de loop van de tijd, zij het enkele dagen na het hegin, of vele of enkele malen in milliarden jaren, scheppend in deze werkelijkheid heelt ingegrepen.

Tegen deze beschouwingen kumnen echter enkele bezwaren worden aangevoerd. Deze gelden niet de ecrste, dic wij momenteel als geheel verouderd ter zijde kunnen stellen, maar voomamelijk de andere drie. 1. Het cerste en belangrijkste bezwaar is wel dit, dat in deze opvattingen de scheppingsdaad Gods gebruikt wordt om bepaalde vraagstukken op te lossen, waar de wetenschap mee worstelt. In hen allen zit in meerdere of mindere mate nog iets van de toepassing van teksten ter verklaring van wetenschappelijke problemen.

2. Een tweede hezwaar tegen deze opvattingen betreft de aanwijsloarheid en localiseerbaarheid van Gods werk. Wanneer de natuurwetenschap met zekerheid zou aantonen dat in een bepaald gebied in cen bepaalde tijd de eerste vissen optraden, dan zou bv. de derde hierboven geschetste opvatting tot de conclusie kunnen komen dat daar en toen dàt door God geschapen is. Dit nu ligt heslist buiten de menselijke bevoegdheid en capaciteiten, zoals onder meer in Pred. 3 : 11 duidelijk wordt gesteld. Wij kunnen als Christenen Gods hand in ons leven en in deze werkelijkheid in het geloof ervaren en aanvaarden, maar dit is ninmer natuurwetenschappelijk voor ieder evident aantoonbaar en bewijshaar.

3. Een volgend bezwaar tegen deze beschouwingen raakt een geheel ander punt dat beslist niet voor alle aanhangers van bovengenoemde opvattingen geldt, maar dat toch bij het tot stand komen van deze heeft meegespeeld. De ontdekking van vele natuurwetten in de voorgaande eeuwen heeft een invloed gehad op onze voorstellingen van Gods werkzaamheid. Meer en meer kreeg men een loeeld van deze werkelijkheid waarin de natuurwetten autonoom waren, steeds op dezelfde wijze alles beheersend. Meende men vroeger dat alle gebeuren, naar willekeur door de goden of door God momentaan bestuurd wordt, geleidelijk ging men „de natuur" een grote mate van zelfstandigheid tocsehrijven. Deze 
natuur hestond in zichzelf en loopt als een groot mechanisme vanzelf voort. Ook de Cliristenen onder de natuurwetenscliapsbeoefenaars ondergingen de invloed van deze denkstroming en dit stimuleerde de ook bij de scheppingsvragen doorwerkende gedachte, dat hij Gods werkzaamheid in deze werkelijkheid in de natuurwetmatigheid ingegrepen moet worden, de natuurwetten dus doorbroken moeten worden. Deze benadering kan geen zuiver-Christelijke zijn, daar wij toch immers geloven dat er geen mus van het dak of geen haar van ons hoofd kan vallen zonder de wil van God. Van een werkelijke autonomie, van een zelfstandigheid van de natuur tegenover God kan, naar wij geloven, dan ook geen sprake zijn. 4 In de laatste plaats en dit hangt nauw samen met alle drie de voorgaande opmerkingen, kan als bezwaar gevoeld worden dat in deze beschouwingen de cenheid van de schepping doorbroken wordt. Volgens hen valt de schepping in een aantal afzonderlijke in de tijd plaats gehad hebbende daden Gods, die een aanvullend karakter hadden, uiteen. Terwijl wij als cen der grondtonen in de Bijhel menen te verstaan de algemene samenhang van „het ganse schepsel”, die zelfs niet alleen het geschapen zijn, maar eveneens de verworpenheid, de verlossing, en de herschepping hetreft.

Indien dus de vermelde benaderingen van het vraagstuk van schep. ping en evolutie verworpen worden, moet gezocht worden naar een nieuwe, die niet door de bovengenoemde bezwaren getroffen wordt. In het volgende wordt een poging gedaan een eindje in deze richting te vorderen. Allerminst wordt gemeend dat dit nu de definitieve oplossing van alle problemen of zelfs alleen maar van het kernprobleem is, maar men hedenke dat slechts indien pogingen worden gedaan op den duur verder gekomen kan worden. In deze opvatting wordt er van uitgegaan dat deze werkelijkheid als een in al zijn geledingen samenhangende totaliteit van hemel en aarde door een almachtige voor ons absoluut onbegrijpelijke scheppingsdaad Gods in den heginne is geschapen. Sindsdien wordt deze schepping voortdurend, van ogenblik tot ogenblik door God in stand gehouden cn geleid, zonder dat cr ook maar iets een autonomie tegenover Hem bezit. Indien God, bij wijze van menselijk spreken, maar even $Z_{i j n}$ hand zou terug trekken, was er niets van deze schepping over.

Gods totale scheppingsdaad omvatte alles wat voor ons tijdelijke denken in de loop van de wereldgeschiedenis zou plaats vinden. Met de schepping waren zo ook alle schepselen gegeven die in de tijdelijke werkelijkheid naderhand voor ons oog zichtbaar zouden worden. Men kan het misschien ook zo zeggen dat deze totale schepping in de loop van millioenen jaren kaleidoskopisch tot heel haar veelkleurige rijkdom ontplooid is, zoals uit een zaadje een boom met stam en blaren, met bloemen en vruchten te voorschijn komen. 
In deze beschouwingswijze wordt het wonder van Gods scheppende werkzaamheid dus niet gereduceerd tot een zo af en toe plaatsvindende, tot een incidentele, ingrijpende geheurtenis, nee het wonder is totaal, allesomvattend, altijd gelovig ervaarbaar.

Wanneer wij het in een dergelijke radicaal-Christelijke richting zoeken dan smelt het conflict van schepping en evolutie weg, want dan is het evolueren van deze werkelijkheid ontdaan van haar autonoom karakter, en slechts manifestatie van Gods werkzaamheid. Wanneer dan rustig aanvaard of overwogen kan worden dat er een generale, ook genetische, samenhang tussen de dingen bestaat, in die zin dat de eerste levende organismen via een voorbereidingsweg van complicatie van levenloze dingen, en ook dat de mens via de lijn der gewervelde dieren tot aanzijn is gekomen, dan missen deze beschouwingen de religieuze spanning die vroegere opvattingen steeds meel,rachten, want het "nieuwe" is dan niet volstrekt nieuw, en het nieuwe is ook niet herleidbaar tot het voorgaande, maar het is in diepste zin geworteld in de schepping.

Hoewel deze opvatting wat de feitelijke zijde betreft veel overeen. stemming heeft met het evolutionisme, is het duidelijk dat de gehele benadering een andere is. Tegenover de gedachte van de herleidbaarheid der aspecten worden radicale verschillen gehandhaafd. Tegenover de autonomie van de natuur wordt haar volstrekte afhankelijkheid van Gods leiding gesteld. Terwijl bij het evolutionisme de gedachte aan een doel in de evolutie ontbreekt, zal de Christen dit duidelijk zien in de mens, die de overige schepping dient te onderwerpen, en God bewust kan loven en eren. De zin van deze gehele ontwikkelende werkelijkheid is haar op God gerichtheid, haar in alle geledingen heenwijzen naar Zijn majesteit.

Kortom wij zullen niet slechts het evolutionisme moeten verwerpen, maar tevens daarvoor in de plaats een eigen beschouwing moeten ontwerpen die, uitgaande van de scheppingsopenbaring in de Bijbel, reken. schap aflegt van de zeer grote hoeveelheid gegevens die de natuurwetenschap ten gunste van de evolutie-gedachte heeft aangevoerd.

Een dergelijke beschouwing zal echter pas waarlijk Christelijk zijn indien hierin, zoals hierboven reeds terloops werd gesteld, niet alleen wordt uitgegaan van de scheppingssamenhang van alle dingen, maar wanneer wij gaan inzien dat het Christus is die in de hele wereldgeschiedenis centraal staat. Men denke aan Col. I : 15-20: „Hij is het beeld van de onzichthare God, de ecrstgeborene der ganse schepping, want in Hem zijn alle dingen geschapen, die in de hemelen en die op de aarde zijn, de zichthare en de onzichthare, hetzij tronen, hetzij heerschappijen, hetzij overheden, hetzij machten; alle dingen zijn door Hem en tot Hem geschapen; en $\mathrm{Hij}$ is vór alles en alle dingen hebben hun bestaan in 
Hem; en Hy is het hoofd van het lichaam, de gemeente. Hy is het legin, de eerstgeborene nit de doden, zodat $\mathrm{Hij}$ onder alles de eerste geworden is. Want het heeft de ganse volheid behaagd in Hem woning tc maken, en door Hem, vrede gemaakt hebhende door het bloed zijns kruises, alle dingen weder met Zich te verzoenen, door Hem, hetzij wat op de aarde, hetzij wat in de hemelen is".

$\Lambda$ msterdam.

J. Lever.

[Dit is vir Koers ' $n$ voorreg om hierdic eerste van 'n reeks van drie artikels wit die hand van prof. dr. J. Lener, die gevierde bioloog ann die Vrye Universiteit te Amsterdam, te publiseer. Die volgende tuee artikels sal in opvolgende nommers verskyn. Indien enige van ons lesers na plasing van al drie artikels op die s/cllings van prof. Lever in ons diskussie-rubriek wil reageer sal dit verwelkom w'ord, en moontlik sal prol. Lever ons vereer met 'n repliel. - Redakteur.] 